\title{
Intraoperative support during lung transplantation
}

\author{
Pedro Reck dos Santos, Jonathan D'Cunha \\ Department of Cardiothoracic Surgery, Mayo Clinic Arizona, Phoenix, AZ, USA \\ Contributions: (I) Conception and design: Both authors; (II) Administrative support: J D’Cunha; (III) Provision of study materials or patients: Both \\ authors; (IV) Collection and assembly of data: Both authors; (V) Data analysis and interpretation: Both authors; (VI) Manuscript writing: Both \\ authors; (VII) Final approval of manuscript: Both authors. \\ Correspondence to: Jonathan D'Cunha, MD, PhD. Department of Cardiothoracic Surgery, Mayo Clinic Arizona, 5777 E Mayo Blvd, Phoenix, AZ \\ 85054, USA. Email: DCunha.Jonathan@mayo.edu.
}

\begin{abstract}
The role of intraoperative mechanical support during lung transplantation (LTx) is essential to provide a safe hemodynamic and ventilatory status during critical intraoperative events. This hemodynamic and ventilatory stability is vital to minimize the odds of suboptimal outcomes, especially considering that, due to the scarcity of donors and the fact that more and more patients with significant comorbidities are being considered for this therapy, a more aggressive approach is often needed by the transplant centers. Hence, the attenuation of any potential injury that can happen during this complex event is paramount. While a thorough assessment of the donor and optimization of postoperative care is pursued, certainly protective intraoperative management would also contribute to better outcomes. Understanding each patient's underlying anatomy and cardiopulmonary physiology, associated with awareness of critical events during a complicated procedure like LTx, is essential for a precise indication and safe use of support. Cardiopulmonary bypass (CPB) and veno-arterial extracorporeal membrane oxygenation (VA ECMO) have been the most common approaches used, with the latter gaining popularity more recently and we have used VA ECMO exclusively for the last decade. New technologies certainly contributed to more liberal use of VA ECMO intraoperatively, enabling a protecting and physiologic environment for the newly implanted grafts. In this setting, potential prophylactic use for lung protection during a critical period is also considered.
\end{abstract}

Keywords: Lung transplantation (LTx); veno-arterial extracorporeal membrane oxygenation (VA ECMO); venovenous extracorporeal membrane oxygenation (VV ECMO); intraoperative support; cardiopulmonary bypass (CPB); end-stage lung diseases; primary graft dysfunction (PGD); acute lung injury (ALI)

Submitted Jul 15, 2021. Accepted for publication Jul 30, 2021.

doi: $10.21037 /$ jtd-21-1166

View this article at: https://dx.doi.org/10.21037/jtd-21-1166

\section{Introduction}

Lung transplantation (LTx) has become the mainstay for managing end-stage lung diseases, and many factors can negatively impact the outcomes of patients submitted to this therapy (1). Among these, acute lung injury (ALI) is the most important and extensively studied. It can occur due to suboptimal management during many phases of the transplant process, like during donor preservation, intraoperative period, and immediate postoperative recovery, constituting one of the most important prognostic factors associated with long term outcomes (2). Primary graft dysfunction (PGD) is associated with ALI and negatively affect the outcomes of patients submitted to LTx (3) and also is related to downstream development of chronic lung allograft disease (4) and mortality (5).

These critical injuries can happen in many stages of the LTx journey, and the prevention or attenuation of the impact of these factors will require a thorough assessment of many aspects. In this situation, it is vital to have a comprehensive approach to the donor and recipient, including the intraoperative period. In this situation, it is vital to have a comprehensive approach to the donor and recipient, including the intraoperative period (6). 
Management of the intraoperative period focusing on minimizing the stress to the patient and the grafts is essential to attenuate the injury to the lungs. ALI is considered the trigger for a cascade of events that can eventually lead to suboptimal outcomes. An intraoperative period with protective ventilation combined with adequate hemodynamic support is essential to minimize lung injury. However, in many cases, it cannot be feasible without additional mechanical help (7).

Due to the complexity and variability of each patient, LTx is achievable without hemodynamic support like in patients with COPD, cystic fibrosis, young patients, or single-LTxs (according to the indication) (8). But when a stable surgery cannot be maintained or is not sustainable, some intraoperative support is necessary. Critical moments like during pneumonectomy, when the remaining or the newly implanted graft lung is responsible for maintaining the patient's status, or during the induction of anesthesia in a patient with severe pulmonary hypertension are examples (9).

\section{Rationale for intraoperative support use}

The objective of intraoperative support is to maintain hemodynamic and ventilatory stability for the patient. As a consequence, reducing stress to the newly implanted grafts can bring benefits which have the potential for short and long-term gains.

During LTx, mechanical support can be necessary to address hemodynamic instability and poor oxygenation. Hypoxia and hypercarbia needed to be adjusted to maintain a stable period of transplantation (10). A thorough assessment of each patient's clinical status is undoubtedly beneficial in evaluating patients that can require intraoperative support. And approximately $40-50 \%$ of patients will require mechanical assistance during transplantation $(11,12)$. A transplant performed without support can bring inevitable consequences like the grafts' exposure to the entire cardiac output (13) and to a ventilatory regimen constituted by high airway pressures, increasing the odds of injury during reperfusion (14).

While the purpose of intraoperative support was to provide complete control of the patient's hemodynamic/ ventilatory status in the past, more recent data has been moving towards a benefit related to a protective environment for the grafts. In the same way that $e x$ vivo lung perfusion has been used to minimize/optimize the function of marginal donor lungs to increase the number of transplants $(15,16)$ intraoperative support can also be a tool protect the grafts and attenuate lung injury.

One of the aims of intraoperative support is to ensure stability during that critical period. Protection of the new grafts during that early reperfusion stage is essential. A slow release of the pulmonary artery showed to be beneficial for the initial reperfusion of the lungs (17), so if we expand this rationale, in theory, prolongation of this concept can likely diminish injury related to reperfusion of the new lungs, which is so critical for the overall success of LTx (18).

The window of opportunities that this concept brings to the table is critical. Ischemia-reperfusion syndrome has many etiologies, but certainly, a way to diminish the impact of this harmful event is to provide an environment that does not add injury to the lungs. During LTx, it is necessary to expose the lungs to very high airway pressures, tidal volumes, and $\mathrm{FiO}_{2}$, mostly when cases are done off support because single lung ventilation needs to be done by the native and especially by the newly implanted graft. In this context, if we have a condition to offer a ventilatory regiment that protects the lungs, potential benefits could be expected to attenuate ALI (19). A physiological and pulsatile flow in the pulmonary artery during reperfusion can add some layer of protection to this strategy (20).

Historically, the association between intraoperative support and ALI was frequently reported as an undesirable effect $(21,22)$. However, new technologies used in scenarios where lung protection is essential (ARDS) are reassuring these concepts (23).

\section{Indications for intraoperative support}

LTx is considered a complicated procedure for various patients, and understanding each patient's needs is critical to achieving good outcomes. When we think of circulatory support, a thorough assessment of the candidate is essential in order to fill the gap in each patient's needs. In this sense, while we discuss intraoperative support, it is crucial to understand that, in many instances, mechanical assistance may be required even before the surgical procedure and can extend beyond the moment that the patient is in the operative room. While the scope of this review is related to intraoperative support, it is essential to note that this concept shows three scenarios:

* Patients who are already using mechanical support before LTx, where the system used as a bridge to LTx is maintained or switched to a different configuration. The most common situation is patients with respiratory failure who use support to correct this 
deficiency, like veno-venous extracorporeal membrane oxygenation (VV ECMO) (24). VV ECMO can be maintained intraoperatively, and sometimes LTx is completed only with this support. Still, a change in the configuration can be necessary according to the intraoperative findings. If concerns during the intraoperative period, installing a regiment that offers hemodynamic support is needed. In these situations, a change in the perfusion system's configuration is mandatory, and the VV ECMO circuit already being used can become more commonly VA ECMO or other hybrids ECMO configuration or have its perfusion circuit used in conventional CPB (25).

* Patients who present with hemodynamic instability immediately before LTx or who have a very high likelihood of decompensation during anesthesia induction. This concerning situation is often associated with patients with primary pulmonary hypertension $(\mathrm{PPH})$ or those with end-stage lung disease where severe right ventricular (RV) dysfunction is found, like scleroderma. Anesthesia induction is a critical moment when circulatory collapse can happen, and support is needed emergently (26). Often, awake VA ECMO needs to instituted using a femoral configuration when the patient presents in such a critical condition, and cardiocirculatory collapse is imminent (27).

* Patients who require support during the surgery and in this case, the assistance is generally started during critical moments, like during pneumonectomy and implantation of the grafts, where the remaining lung or the newly implanted graft is responsible for providing support. In this scenario, intraoperative support generally follows indications like:

- Single lung ventilation is not tolerable/sustainable (high $\mathrm{FiO}_{2}$ is necessary, $\mathrm{CO}_{2}$ cannot be adequately removed, supraphysiologic airway pressures are needed)

- Systolic PA pressure $>50 \mathrm{mmHg}$ with occlusion of the contralateral PA indicates that the patient will not tolerate a pneumonectomy. Here, the use of support to avoid RV dysfunction is needed (28).

- Emergencies like bleedings from the pulmonary artery/left atrium indicate mechanical support to fix these catastrophic events.

- Anatomical challenges, like a problematic exposure of the hilum, especially on the left side and in cases where the chest is small (29). Difficulties in the airway anastomosis can also require support for the stabilization of the patient

- Disease-related issues where intraoperative support is anticipated, like patients with PPH or IPF with concomitant RV dysfunction, are examples of this situation (30), where anticipation and reduction of the patient's stress are crucial. Also, patients where additional cardiac procedures are required, like valve replacements or CABG, constitute specific indications for support. As LTx programs become more aggressive and patients more and more sick are being listed, situations like patients with moderate coronary artery disease can also benefit from intraoperative support to reduce stress to the heart during LTx.

- Donor-related issues are also aspects where intraoperative support must be considered, especially in cases with marginal/high-risk donors. The rationale here is that considering the suboptimal function identified, it seems intuitive that reducing the graft's stress during implantation will be necessary, attenuating ischemia-reperfusion injury. In this category, we also include grafts with extended ischemic time, anticipating that this situation's primary function cannot be the expected, and the avoidance of further stress may enable better long-term outcomes. Lobar transplants are also a topic that deserves consideration because of its restricted vascular "bed" of the lobes, which will be implanted and subjected to a whole cardiac output; intraoperative support seems like a reasonable option, guaranteeing appropriate support for the patient (31).

\section{Modalities of intraoperative support}

Intraoperative support focuses on addressing ventilatory and circulatory issues. The modalities commonly used are cardiopulmonary bypass (CPB) and ECMO.

\section{$C P B$}

CPB provides essential points like complete control of the patients' hemodynamic status, allowing an easy way to handle critical events during LTx (32) and historically is associated with good outcomes after transplantation $(33,34)$. The technique of CPB is described in detail elsewhere (35). In contrast to the CPB strategy used for conventional 
cardiac surgery procedures, during LTx, this modality supports the circulation/ventilation and unloads the heart. In this sense, it is very unusual to use cardioplegic solutions, perform aortic cross-clamping, and cardiac arrest. CPB offers these tools for the rare catastrophic events that may occur, like left atrium tears, major atrial reconstructions, or combined cardiac and intracardiac procedures.

Although CPB has some major advantages for LTx, there are a series of limitations which can have a profound influence on recovery and outcomes. An example is the inflammatory response associated with lung injury. In the setting of LTx, additional damage to the grafts can become critical for long-term outcomes (36). In addition to this, $\mathrm{CPB}$ uses an open perfusion system (enabling a blood-air interface), requires large prime volumes, and does have an extended surface area of contact, which, taken together, predispose to a more inflammatory reaction. Hence, full anticoagulation is required, which increases the blood turnover. Despite the clear indication for intraoperative support, CPB's use has also considered a risk factor for PGD (10) and suboptimal outcomes (37). CPB is also associated with injury to other organ systems, like renal (38) and neurological (39).

The importance of CPB resides because this is a system that provides complete control of the hemodynamic status. It is useful to have a hybrid pump or a CPB system available in the OR for situations where the general VA ECMO cannot guarantee a stable hemodynamic status. In this circumstance, the transition from VA to CPB is mandatory. Here, the use of a pump sucker may reduce the blood loss (during significant bleedings demanding massive blood transfusions). CPB is also needed when a cardiac repair is necessary (reconstruction of the atrium) or concomitant cardiac procedures are required (repair of cardiac defect, valve surgery, $\mathrm{CABG}$ ).

The ability to initiate $\mathrm{CPB}$ with the use of a hybrid pump is vital in situations like problematic hilar exposure using VA ECMO only, where retraction of the heart is associated with hemodynamic decompensation. The necessity to mobilize further or drain the heart more effectively becomes essential. Under these situations, CPB can be used temporarily, with the reinstitution of VA ECMO after the problem is solved (i.e., left lung transplants with problematic exposure). An available and "ready to go" $\mathrm{CPB}$ system gives flexibility for the surgeon to, as an example, start a case off-pump, go in VA ECMO, and if needed, a transition to $\mathrm{CPB}$ to solve any emergency and go back to $\mathrm{VA} / \mathrm{VV}$ ECMO, according to the situation.

\section{Extracorporeal membrane oxygenation}

ECMO has been a modality of extracorporeal support, which has gained popularity due to several improvements in the technique that has contributed to its safe use.

It is undeniable that ECMO also is associated with an inflammatory response (40). Still, new technologies contributed to attenuating and providing a safer option than the traditional modality of support offered. Some key components deserve attention like centrifugal pumps (which generates less trauma to blood cells), tubing lines that are heparin-coated, and new oxygenators where polymethyl pentene is crucial (mainly due to its properties in reducing plasma leaks and protein break and preventing the formation of microbubbles). A better understanding of each patient (more precise indications) has also been essential for the progressive, positive impact that ECMO has been showing in the clinical scenario (41). Here, ECMO has its role as a bridge to transplant (42) and as a recovery tool after transplant (43).

The intraoperative ECMO setting most commonly comprises two modalities, which are:

\section{VV ECMO}

This modality has been used in the management of ARDS (44) and in many instances during Thoracic Surgeries to facilitate the resection of malignancies, complex surgical procedures involving the airways, etc. (45). VV ECMO can provide adequate oxygenation but cannot fix hemodynamic instability. Hence, its use as intraoperative support is restricted. COPD patients where oxygenation is not optimal, and heart function is sufficient, or cystic fibrosis under basically the same conditions, are examples of patients that can benefit from it. Another situation would be when, immediately after anesthesia induction, ventilation becomes an issue with non-compliant lungs such that VV ECMO is used to maintain ideal ventilation and oxygenation during LTx. The RV must have adequate function or be supported with adjuncts and the surgeon is looking to have a stable oxygenation status throughout the case. It is important to remember that, despite being considered a more straightforward and more uncomplicated system to manage in comparison to VA ECMO, it does not address critical issues like unloading of the right ventricle and hemodynamic support (46).

The VV ECMO cannulation has many configurations, like a single-site using a dual-lumen cannula (46). We described the traditional 2-site approach. The femoral 
vein (FV) drains deoxygenated blood, while in the internal jugular (IJ) vein, oxygenated blood enters the circulation.

Using ultrasound, a right common $\mathrm{FV}$, and the right $\mathrm{IJ}$ are identified and punctured. Heparin is administrated utilizing a dose of 40-60 IU/kg, and guidewires introduced. Cardiac arrhythmia signal successful wire introduction into the right side of the heart. A $25 \mathrm{Fr}$ multistage cannula is inserted using a Seldinger technique in the FV, while a 19-21 Fr Single Stage Cannula is inserted in the right IJ following sequential dilation to a size just below the desired cannula diameter. If one is able to avoid overdilation, the risk of local complications from leakage around the cannula is minimized. If desired for evaluation of wires and cannulas, fluoroscopic or transesophageal echo (TEE) guidance can be useful. Some groups use spot checks with $\mathrm{X}$-rays. Occasionally we have used surface ultrasound on a thin patient. Cannulas are secured with 0 silk pursestring sutures at the skin level along with at least 4 additional 0 -silk sutures along the cannulas at the level of the skin. It is always essential to have a previous discussion with the perfusion team about the size of cannulas and the needs that each patient will have. The final position of the cannulas can be confirmed using transesophageal ultrasound (TEE) or any of the above mentioned methods.

Once cannulas are connected to the ECMO system, flows are adjusted to keep adequate oxygenation during the case, and ACTs between 140-180 are maintained. Again, we stress that this modality of support does not provide hemodynamic support. A low threshold for a change in the configuration to support, which enables circulatory stability, is essential.

At the end of the procedure, if the clinical condition permits, VV ECMO can be removed by simply pulling the cannulas, securing the percutaneous access sites with a 0 Prolene pursestring suture and applying local compression to the vessels for 15-30 minutes. If necessary, VV ECMO can be extended to the postoperative period.

\section{VA ECMO}

This approach has surpassed the use of $\mathrm{CPB}$ as the intraoperative support of choice during LTx and provides both hemodynamic and ventilatory support. The use of VA ECMO also has been critical in some specific situations during complex thoracic surgeries, like the resection of locally advanced malignancies (47). Regarding LTx, ECMO's use as a replacement tool for the CPB is not new $(48,49)$, and the potential advantages of this system have been highlighted and reported.
The use of a smaller perfusion circuit constituted basically by oxygenator, heat exchanger, cannulas, and the tubing lines facilitates the management. This circuit does not have a cardiotomy reservoir (avoiding the bloodair interface), which undoubtedly contributed to fewer bleeding-related issues. The anticoagulation requirements are less compared to $\mathrm{CPB}$. In addition to this, protamine is generally not required, avoiding the effects of the protamine-heparin interactions regarding inflammatory response (50).

Recently accumulating literature has been showing the benefits of VA ECMO when compared to CPB. Although these reports are mainly single-center, retrospective, where heterogeneous groups of patients were analyzed and compared to historical controls (considering that cases done with CPB were more often performed in the past) while centers are now accumulating and transitioning to VA ECMO as the approach of choice, it is undeniable that the cumulative experiences by large volume centers have been showing the benefits of VA ECMO.

Our team showed that VA ECMO was used in patients with higher LAS scores than $\mathrm{CPB}$, and even under this condition, the VA ECMO group was associated with less tracheostomy, reintubation, and renal failure requiring dialysis. However, no differences in PGD or need for blood transfusions, neither in 30-day (CPB 5\% vs. VA ECMO $4.1 \%$ ) and 6-month mortality (14.4\% CPB vs. $14.3 \%$ ECMO) was demonstrated (51). These findings were also described in another report by a different group. Still, in this report, VA ECMO showed fewer blood transfusions, less bleeding issues, and a smaller number of reoperations than $\mathrm{CPB}$. They did find less PGD in the VA ECMO group, though, without significant impact in both the 30 day and 1-year survival (52).

The Hannover group initially demonstrated a survival benefit with VA ECMO, and the substantial reduction of the in-hospital mortality was one of the leading causes associated with these better outcomes (39\% CPB vs. 13\% in the VA ECMO group). The fact that the CPB group was associated with more blood and platelet concentrate transfusions, more dialysis, and new postoperative ECMO support certainly contributed to the elevated In-Hospital mortality verified in the $\mathrm{CPB}$ group, which reflected in a lower 3-, 9- and 12-month survival, when compared to VA ECMO (53). Considering the benefits verified, the same group performed a further analysis where their VA ECMO experience was compared to those patients whose LTx was completed off support. Interestingly, intraoperative VA 
ECMO did not seem to configure a risk factor for longterm survival (54).

Machuca et al. compared VA ECMO to CPB for intraoperative support during LTx and found favorable results in the VA ECMO group in regards to early outcomes, like less mechanical ventilation requirements, shorter ICU and hospital LOS, and lower perioperative blood transfusion requirements. A 90 -day survival of $6 \%$ for the ECMO group, whereas the CPB showed $15 \%$ for this same period, trending towards a survival benefit (55).

Central cannulation is the preferred approach, because it is easier than a peripheral, provides enough flows, and offers room for emergencies, like increased perfusion flows when necessary, or even modifications in the configurations.

While during CPB full heparinization is required, VA ECMO can start after a single dose bolus of Heparin 40$60 \mathrm{U} / \mathrm{Kg}$. Cannulation of the ascending aorta requires an 18 or $20 \mathrm{Fr}$ single-stage cannula. For the atrial cannulation, a single-stage atrial cannula provides enough drainage to maintain the VA ECMO circuit. A double-stage atrial cannula can also be used and is our preference. It is essential to have an ACT $>200 \mathrm{~s}$ for aortic cannulation, and maintenance of the VA ECMO will require an ACT between 180-200 s.

Since there is a risk of air embolism, two concentric purse strings are used in the right atrium to minimize the chances of air entering the system. We also lay a small sponge circumferentially around the cannula at the entry site on the atrium. When VA ECMO is initiated, we prefer a CVP $>5$ and initiate VA ECMO slowly such that the CVP does not drop significantly and the hemodynamics are maintained. All of these maneuvers are aimed in ensuring "zero chance" of air entering the system. During the case, it is critical that our anesthesia colleagues keep the CVP $>5$ and have dialogued with the surgical team actively. Arterial blood gasses are sent every 30 minutes along with an ACT measurement. Coagulation parameters are checked every hour for the rest of the case. Perfusion flows are maintained at $40-50 \%$ of the cardiac output, which provides enough support. As emphasized above, it is vital to maintain an adequate volume status of the patients to avoid situations where low-flow can typically occur, like during retraction or heart, or when a left atrium clam is applied. Volume status is frequently checked using TEE by the anesthesia team.

During the conduct of the operation, the use of a hybrid pump allows for greater flexibility. If there are significant issues with hemodynamics or exposure, once can fully heparinize and use the same circuit to go on $\mathrm{CPB}$ with minutes. Also, since ECMO cannot return lost blood like when the patient is on $\mathrm{CPB}$, it is our recommendation that if the transfusion requirement starts to go above 4-6 units of blood, the operative team should strongly consider going on $\mathrm{CPB}$ at that point and using the cardiotomy suckers and advantages of CPB to return blood to the patient. Although the use of cell saver during the case up to that point can be helpful, the operative situation can call for more minute to minute management of volume and blood return which is aided by CPB.

During reperfusion of the lungs, the pump flow should be titrated to allow reperfusion with a pulsatile and physiologic PA pressure $(15-20 \mathrm{mmHg})$, maintaining protective ventilation to the grafts with adequate volume status. During a bilateral sequential lung transplant, once the first lung has been sewn in and reperfused, the new graft should be ventilated with a protective strategy until the second graft is reperfused. According to the necessity, ECMO can be discontinued or switched to a different modality at the end of the case.

Variations of this modality include using the femoral vein as the drainage site instead of the right atrium, which is the case in single-LTxs or in instances where the patients are already using some form of ECMO before LTx.

Peripheral VA ECMO can also be used for intraoperative support during LTx (56). Still, in general, this approach is applicable for those patients who present with sudden deterioration during anesthesia induction or those who are so critically ill that are already using this system before the transplant (awake VA ECMO insertion). The technique is similar to the central cannulation described above. There are a few related differences, especially regarding the vessels' surgical approach, which can be done percutaneously or using a cutdown.

The femoral artery is localized and punctured using a percutaneous approach, with the help of an ultrasound, and a single-stage 15-19 Fr cannula is inserted via the Seldinger technique. A 21-25 Fr multistage cannula is also inserted in the ipsilateral or contralateral femoral vein. It is advisable to insert a $7 \mathrm{Fr}$ distal perfusion cannula in the femoral artery to nourish and avoid the leg's ischemia.

At the end of the transplant, this modality of support can be maintained, weaned, or switched to a different configuration like VV ECMO, according to each patient's necessity. Of note, an open repair of the femoral artery cannulated is generally required when this modality is weaned. 


\section{Complications of intraoperative support}

The use of intraoperative support is associated with complications. Although critical events have been trending down over the years, it is always important to be aware of the potential issues. One of the most important ways to prevent complications is to choose a proper setup with a configuration that attends to each patient's needs. In addition to this, cannulations performed on an elective basis present fewer complication than those done on an emergency basis. It is vital not to underestimate how important it is to have a thorough assessment of the patient, recognizing and anticipating, if possible, potential risks that may be associated with these dramatic events. A review of the exams and the use of ultrasound for vessel assessment are critical to recognize situations like calcified vessels, anatomical variants, among others, that can increase the risks for complications.

It is imperative to stress that vascular access needs to be carefully done to minimize events associated with direct lesions to the vessels cannulated, like hemorrhages, hematomas, arterial dissections, and thrombosis (57). While central cannulation is generally associated with fewer complications than a peripheral approach, events like bleedings, hematomas, and even arterial dissections can occur (58).

A critical issue that deserves attention is air emboli, mostly with VA ECMO. Because of the configuration system used, the prevention of this event is paramount. Avoidance of the administration of solutions in the ECMO system ports or using two concentric purse-string sutures while cannulating the right atrium are ways to minimize this risk.

During peripheral cannulations, it always necessary to use an ultrasound-guided technique for cannulation. This is critical in cases of $\mathrm{VV}$ ECMO when an IJ-FV approach is used, and proper insertion and crucial position of the cannulas are mandatory for achieving the expected results.

Another key point is that peripheral VA ECMO requires vessels' cannulation, which sometimes has a relatively small size. The likelihood of accidents like dissections and hematomas is higher in this setting, and ischemia of the extremities needs to be followed closely after cannulationthe insertion of a distal perfusion cannula is a critical factor in preventing this severe event. When VA ECMO is decannulated, a repair of the artery is usually necessary to minimize stenosis and other complication. Peripheral cannulation is also associated with seromas and infections in the groin, and a constant assessment of that area is critical.

\section{Expanding the indication for intraoperative support - prophylactic VA ECMO}

Many centers have reported VA ECMO's benefits as the intraoperative support of choice. The opportunities that ECMO presents, in comparison to the potential hazardous effects that $\mathrm{CPB}$ has shown, clearly suggest that ECMO is becoming a safe and effective way to provide intraoperative support during $\mathrm{LTx}_{\mathrm{x}}$ (59),

Based on the results presented so far, and considering the protective opportunities that ECMO can provide and the low risk of complications that this therapy presents, more liberal use of ECMO during LTx is potentially the next step regarding lung protection and preservation.

Many lung transplants centers face a current problem: the scarcity of donors and the fact that patients with significantly more comorbidities and with advanced ages for LTx are listed, which happens very often with patients with pulmonary fibrosis (60). It becomes crucial to minimize perioperative complications and improve the outcomes. The more liberal use of a tool that can protect the grafts intraoperatively, allow a safe surgical procedure, and diminish this aggression's impact on other organs like the heart, brain, and kidneys makes sense.

Data showing that LTx performed off support and VA ECMO have similar outcomes. VA ECMO was associated with a more complicated perioperative and immediate postoperative period (maybe reflecting the patients' severity that required this support during LTx). Still, patients who survived Hospital discharge showed no significant repercussions regarding long-term effects and complications (61).

In this sense, VA ECMO can provide a stable environment to use protective hemodynamic and ventilatory strategies. Besides, a more liberal volume reposition strategy (considering the importance of the maintenance of the ECMO flows) and PA pressures withing a physiologic range (62) will enable controlled reperfusion in the grafts, minimizing injury to the lungs (63).

Hoetzenecker has described this concept of prophylactic ECMO. In their series, patients submitted to LTx with ECMO, compared to those done off support, showed better survival at 1, 3- and 5-years. The authors stress the importance of intraoperative ECMO in what they called a "vicious cycle of early reperfusion injury". Here, lungprotective ventilation and controlled reperfusion deserve special attention. The focus moves towards a strategy that protects instead of providing support only (64). The same group also reported a result of their prophylactic 
VA ECMO, with very low rates of PGD, which gives support and rationale to their hypothesis and move the focus towards the interruption/attenuation of the vicious reperfusion cycle described (65).

\section{Conclusions}

In summary, we believe that intraoperative support, when indicated, clearly benefits the patients. With the advancement of the perfusion systems like ECMO, a more liberal approach can help more and more patients, especially those critically sick. The associated low rate of complications and the potential benefits this therapy can have in the lung transplant population's outcome are strong reasons to consider its use as a prophylactic tool that can lead to better results. There is no doubt that avoiding the inflammatory response associated with ECMO or $\mathrm{CPB}$ is the most ideal situation. However, the emerging data on outcomes and the theoretical benefits of controlled reperfusion are enticing. It is our belief that the use of ECMO intraoperatively in the vast majority of candidates will provide durable long term advantages and we look forward to the analysis of the prospective multi-institutional database trials in the future.

\section{Acknowledgments}

Funding: None.

\section{Footnote}

Provenance and Peer Review: This article was commissioned by the editorial office, Fournal of Thoracic Disease for the series "Lung Transplantation: Past, Present, and Future". The article has undergone external peer review.

Conflicts of Interest: Both authors have completed the ICMJE uniform disclosure form (available at https:// dx.doi.org/10.21037/jtd-21-1166). The series "Lung Transplantation: Past, Present, and Future" was commissioned by the editorial office without any funding or sponsorship. JDC served as the unpaid Guest Editor of the series and serves as an unpaid editorial board member of fournal of Thoracic Disease from February 2021 to January 2023. The authors have no other conflicts of interest to declare.

Ethical Statement: Both authors are accountable for all aspects of the work in ensuring that questions related to the accuracy or integrity of any part of the work are appropriately investigated and resolved.

Open Access Statement: This is an Open Access article distributed in accordance with the Creative Commons Attribution-NonCommercial-NoDerivs 4.0 International License (CC BY-NC-ND 4.0), which permits the noncommercial replication and distribution of the article with the strict proviso that no changes or edits are made and the original work is properly cited (including links to both the formal publication through the relevant DOI and the license). See: https://creativecommons.org/licenses/by-nc-nd/4.0/.

\section{References}

1. Pierre AF, Keshavjee S. Lung transplantation: donor and recipient critical care aspects. Curr Opin Crit Care 2005;11:339-44.

2. Tang PS, Mura M, Seth R, et al. Acute lung injury and cell death: how many ways can cells die? Am J Physiol Lung Cell Mol Physiol 2008;294:L632-41.

3. Balsara KR, Krupnick AS, Bell JM, et al. A single-center experience of 1500 lung transplant patients. J Thorac Cardiovasc Surg 2018;156:894-905.e3.

4. Weigt SS, DerHovanessian A, Wallace WD, et al. Bronchiolitis obliterans syndrome: the Achilles' heel of lung transplantation. Semin Respir Crit Care Med 2013;34:336-51.

5. Sabashnikov A, Weymann A, Mohite PN, et al. Risk factors predictive of one-year mortality after lung transplantation. Eur J Cardiothorac Surg 2014;46:e82-8.

6. Diamond JM, Lee JC, Kawut SM, et al. Clinical risk factors for primary graft dysfunction after lung transplantation. Am J Respir Crit Care Med 2013;187:527-34.

7. Sellers D, Cassar-Demajo W, Keshavjee S, et al. The Evolution of Anesthesia for Lung Transplantation. J Cardiothorac Vasc Anesth 2017;31:1071-9.

8. McRae K. Con: lung transplantation should not be routinely performed with cardiopulmonary bypass. J Cardiothorac Vasc Anesth 2000;14:746-50.

9. Hayanga JWA, Chan EG, Musgrove K, et al. Extracorporeal Membrane Oxygenation in the Perioperative Care of the Lung Transplant Patient. Semin Cardiothorac Vasc Anesth 2020;24:45-53.

10. Liu Y, Liu Y, Su L, et al. Recipient-related clinical risk factors for primary graft dysfunction after lung transplantation: a systematic review and meta-analysis. PLoS One 2014;9:e92773. 
11. Hoechter DJ, Shen YM, Kammerer T, et al. Extracorporeal Circulation During Lung Transplantation Procedures: A Meta-Analysis. ASAIO J 2017;63:551-61.

12. Kiziltug H, Falter F. Circulatory support during lung transplantation. Curr Opin Anaesthesiol 2020;33:37-42.

13. Verbeek GL, Myles PS. Intraoperative protective ventilation strategies in lung transplantation. Transplant Rev (Orlando) 2013;27:30-5.

14. Gelman AE, Fisher AJ, Huang HJ, et al. Report of the ISHLT Working Group on Primary Lung Graft Dysfunction Part III: Mechanisms: A 2016 Consensus Group Statement of the International Society for Heart and Lung Transplantation. J Heart Lung Transplant 2017;36:1114-20.

15. Cypel M, Yeung JC, Liu M, et al. Normothermic ex vivo lung perfusion in clinical lung transplantation. $\mathrm{N}$ Engl J Med 2011;364:1431-40.

16. Cypel M, Keshavjee S. Strategies for safe donor expansion: donor management, donations after cardiac death, exvivo lung perfusion. Curr Opin Organ Transplant 2013;18:513-7.

17. Pierre AF, DeCampos KN, Liu M, et al. Rapid reperfusion causes stress failure in ischemic rat lungs. J Thorac Cardiovasc Surg 1998;116:932-42.

18. King RC, Binns OA, Rodriguez F, et al. Reperfusion injury significantly impacts clinical outcome after pulmonary transplantation. Ann Thorac Surg 2000;69:1681-5.

19. de Perrot M, Liu M, Waddell TK, et al. Ischemiareperfusion-induced lung injury. Am J Respir Crit Care Med 2003;167:490-511.

20. Siepe M, Goebel U, Mecklenburg A, et al. Pulsatile pulmonary perfusion during cardiopulmonary bypass reduces the pulmonary inflammatory response. Ann Thorac Surg 2008;86:115-22.

21. Apostolakis E, Filos KS, Koletsis E, et al. Lung dysfunction following cardiopulmonary bypass. J Card Surg 2010;25:47-55.

22. Christie JD, Bavaria JE, Palevsky HI, et al. Primary graft failure following lung transplantation. Chest 1998;114:51-60.

23. Del Sorbo L, Cypel M, Fan E. Extracorporeal life support for adults with severe acute respiratory failure. Lancet Respir Med 2014;2:154-64.

24. Hayanga AJ, Du AL, Joubert K, et al. Mechanical Ventilation and Extracorporeal Membrane Oxygenation as a Bridging Strategy to Lung Transplantation: Significant Gains in Survival. Am J Transplant 2018;18:125-35.

25. Hashimoto K, Hoetzenecker K, Yeung JC, et al.
Intraoperative extracorporeal support during lung transplantation in patients bridged with venovenous extracorporeal membrane oxygenation. J Heart Lung Transplant 2018;37:1418-24.

26. de Perrot M, Granton JT, McRae K, et al. Impact of extracorporeal life support on outcome in patients with idiopathic pulmonary arterial hypertension awaiting lung transplantation. J Heart Lung Transplant 2011;30:997-1002.

27. Olsson KM, Simon A, Strueber M, et al. Extracorporeal membrane oxygenation in nonintubated patients as bridge to lung transplantation. Am J Transplant 2010;10:2173-8.

28. Rana M, Yusuff H, Zochios V. The Right Ventricle During Selective Lung Ventilation for Thoracic Surgery. J Cardiothorac Vasc Anesth 2019;33:2007-16.

29. Zuercher AJ, Inci I, Benden C, et al. Intra-operative extracorporeal membrane oxygenation use in pediatric lung transplantation--the Zurich experience. Pediatr Transplant 2013;17:800-5.

30. Shah PR, Boisen ML, Winger DG, et al. Extracorporeal Support During Bilateral Sequential Lung Transplantation in Patients With Pulmonary Hypertension: Risk Factors and Outcomes. J Cardiothorac Vasc Anesth 2017;31:418-25.

31. Mitilian D, Sage E, Puyo P, et al. Techniques and results of lobar lung transplantations. Eur J Cardiothorac Surg 2014;45:365-9; discussion 369-70.

32. Marczin N, Royston D, Yacoub M. Pro: lung transplantation should be routinely performed with cardiopulmonary bypass. J Cardiothorac Vasc Anesth 2000;14:739-45.

33. de Boer WJ, Hepkema BG, Loef BG, et al. Survival benefit of cardiopulmonary bypass support in bilateral lung transplantation for emphysema patients. Transplantation 2002;73:1621-7.

34. Taka H, Miyoshi K, Kurosaki T, et al. Lung transplantation via cardiopulmonary bypass: excellent survival outcomes from extended criteria donors. Gen Thorac Cardiovasc Surg 2019;67:624-32.

35. Bojar RM. Manual of perioperative care in adult cardiac surgery. 2011.

36. Asimakopoulos G, Smith PL, Ratnatunga CP, et al. Lung injury and acute respiratory distress syndrome after cardiopulmonary bypass. Ann Thorac Surg 1999;68:1107-15.

37. Mohite PN, Sabashnikov A, Patil NP, et al. The role of cardiopulmonary bypass in lung transplantation. Clin Transplant 2016;30:202-9. 
38. Heid CA, Khoury MK, Maaraoui K, et al. Acute Kidney Injury in Patients Undergoing Cardiopulmonary Bypass for Lung Transplantation. J Surg Res 2020;255:332-8.

39. Carrascal Y, Guerrero AL, Maroto LC, et al. Neurological complications after cardiopulmonary bypass: An update. Eur Neurol 1999;41:128-34.

40. Millar JE, Fanning JP, McDonald CI, et al. The inflammatory response to extracorporeal membrane oxygenation (ECMO): a review of the pathophysiology. Crit Care 2016;20:387.

41. Cypel M, Keshavjee S. Extracorporeal life support as a bridge to lung transplantation. Clin Chest Med 2011;32:245-51.

42. Strueber M. Extracorporeal support as a bridge to lung transplantation. Curr Opin Crit Care 2010;16:69-73.

43. Oto T, Rosenfeldt F, Rowland M, et al. Extracorporeal membrane oxygenation after lung transplantation: evolving technique improves outcomes. Ann Thorac Surg 2004;78:1230-5.

44. Goligher EC, Tomlinson G, Hajage D, et al. Extracorporeal Membrane Oxygenation for Severe Acute Respiratory Distress Syndrome and Posterior Probability of Mortality Benefit in a Post Hoc Bayesian Analysis of a Randomized Clinical Trial. JAMA 2018;320:2251-9.

45. McRae K, de Perrot M. Principles and indications of extracorporeal life support in general thoracic surgery. J Thorac Dis 2018;10:S931-46.

46. Abrams D, Brodie D, Arcasoy SM. Extracorporeal Life Support in Lung Transplantation. Clin Chest Med 2017;38:655-66.

47. Machuca TN, Cypel M, Keshavjee S. Cardiopulmonary Bypass and Extracorporeal Life Support for Emergent Intraoperative Thoracic Situations. Thorac Surg Clin 2015;25:325-34.

48. Pereszlenyi A, Lang G, Steltzer H, et al. Bilateral lung transplantation with intra- and postoperatively prolonged ECMO support in patients with pulmonary hypertension. Eur J Cardiothorac Surg 2002;21:858-63.

49. Aigner $C$, Wisser $W$, Taghavi S, et al. Institutional experience with extracorporeal membrane oxygenation in lung transplantation. Eur J Cardiothorac Surg 2007;31:468-73; discussion 473-4.

50. Pągowska-Klimek I, Świerzko AS, Michalski M, et al. Activation of the lectin pathway of complement by cardiopulmonary bypass contributes to the development of systemic inflammatory response syndrome after paediatric cardiac surgery. Clin Exp Immunol 2016;184:257-63.

51. Bermudez CA, Shiose A, Esper SA, et al. Outcomes of intraoperative venoarterial extracorporeal membrane oxygenation versus cardiopulmonary bypass during lung transplantation. Ann Thorac Surg 2014;98:1936-42; discussion 1942-3.

52. Biscotti M, Yang J, Sonett J, et al. Comparison of extracorporeal membrane oxygenation versus cardiopulmonary bypass for lung transplantation. J Thorac Cardiovasc Surg 2014;148:2410-5.

53. Ius F, Kuehn C, Tudorache I, et al. Lung transplantation on cardiopulmonary support: venoarterial extracorporeal membrane oxygenation outperformed cardiopulmonary bypass. J Thorac Cardiovasc Surg 2012;144:1510-6.

54. Ius F, Sommer W, Tudorache I, et al. Five-year experience with intraoperative extracorporeal membrane oxygenation in lung transplantation: Indications and midterm results. J Heart Lung Transplant 2016;35:49-58.

55. Machuca TN, Collaud S, Mercier O, et al. Outcomes of intraoperative extracorporeal membrane oxygenation versus cardiopulmonary bypass for lung transplantation. J Thorac Cardiovasc Surg 2015;149:1152-7.

56. Glorion M, Mercier O, Mitilian D, et al. Central versus peripheral cannulation of extracorporeal membrane oxygenation support during double lung transplant for pulmonary hypertension. Eur J Cardiothorac Surg 2018;54:341-7.

57. Reeb J, Olland A, Renaud S, et al. Vascular access for extracorporeal life support: tips and tricks. J Thorac Dis 2016;8:S353-63.

58. Ailawadi G, Zacour RK. Cardiopulmonary bypass/ extracorporeal membrane oxygenation/left heart bypass: indications, techniques, and complications. Surg Clin North Am 2009;89:781-96, vii-viii.

59. Nazarnia S, Subramaniam K. Pro: Veno-arterial Extracorporeal Membrane Oxygenation (ECMO) Should Be Used Routinely for Bilateral Lung Transplantation. J Cardiothorac Vasc Anesth 2017;31:1505-8.

60. Salman J, Bernhard BA, Ius F, et al. Intraoperative Extracorporeal Circulatory Support in Lung Transplantation for Pulmonary Fibrosis. Ann Thorac Surg 2021;111:1316-24.

61. Ius F, Aburahma K, Boethig D, et al. Long-term outcomes after intraoperative extracorporeal membrane oxygenation during lung transplantation. J Heart Lung Transplant 2020;39:915-25.

62. Moreno Garijo J, Cypel M, McRae K, et al. The Evolving Role of Extracorporeal Membrane Oxygenation in Lung Transplantation: Implications for Anesthetic Management. J Cardiothorac Vasc Anesth 2019;33:1995-2006. 
63. Alvarado CG, Poston R, Hattler BG, et al. Effect of controlled reperfusion techniques in human lung transplantation. J Heart Lung Transplant 2001;20:183-4.

64. Hoetzenecker K, Schwarz S, Muckenhuber M, et al. Intraoperative extracorporeal membrane oxygenation and the possibility of postoperative prolongation improve survival in bilateral lung transplantation. J Thorac Cardiovasc Surg 2018;155:2193-2206.e3.

65. Hoetzenecker K, Benazzo A, Stork T, et al. Bilateral lung transplantation on intraoperative extracorporeal membrane oxygenator: An observational study. J Thorac Cardiovasc Surg 2020;160:320-327.e1.

Cite this article as: Reck dos Santos P, D'Cunha J. Intraoperative support during lung transplantation. J Thorac Dis 2021;13(11):6576-6586. doi: 10.21037/jtd-21-1166 